\title{
Functional evaluation of patients with hip arthritis after plateled rich plasma hip injection
}

\author{
Radosław Gut MD, PhD; Jakub Kosiński MD; Juliana Woszczyło MD \\ Department of Rehabilitation and Orthopaedics \\ Medical Univeristy of Lublin, Poland
}

Introduction: Platelet rich plasma (PRP) is used in the treatment of patients with osteoarthritis. There are reports in the literature that PRP injections may relate to pain relief and functional improvement.

Purpose: Evaluation of clinical symptoms and functional impairment related to hip arthritis (HA) after concentrated PRP (cPRP) intraarticular injection.

Method: 15 patients ( 7 men, 8 women) with symptomatic HA received $c$ PRP Angel $\otimes$ injection into the hip joint under ultrasound guidance. Assessment of the functional status with the use of the Harris Hip Score (HHS) and WOMAC $®$ scales was performed just before the procedure and after 5 months.

Results: On follow-up, the HHS score increase and WOMAC $®$ score decrease were revealed in 11 persons (5 men, 6 women)

Pain reduction in HHS, and functional ability improvement in WOMAC® were statistically significant, whilst any significant changes of mobility have not been reported. The WOMAC $\AA$

score changes were correlated with pre-treatment scores (Spearman rank test, $p=0.63$ ), so that in persons with higher scores (i.e. lower functional ability) the changes were higher than in those with lower scores.

Conclusions: A single intraarticular injection of concentrated PRP appears to be an effective remedy to improve the functional abilities in patients with HA for 5 months. The criteria of eligibility

for the described method need to be specified in order to evaluate its economical effectiveness and the expected duration of symptom remission.
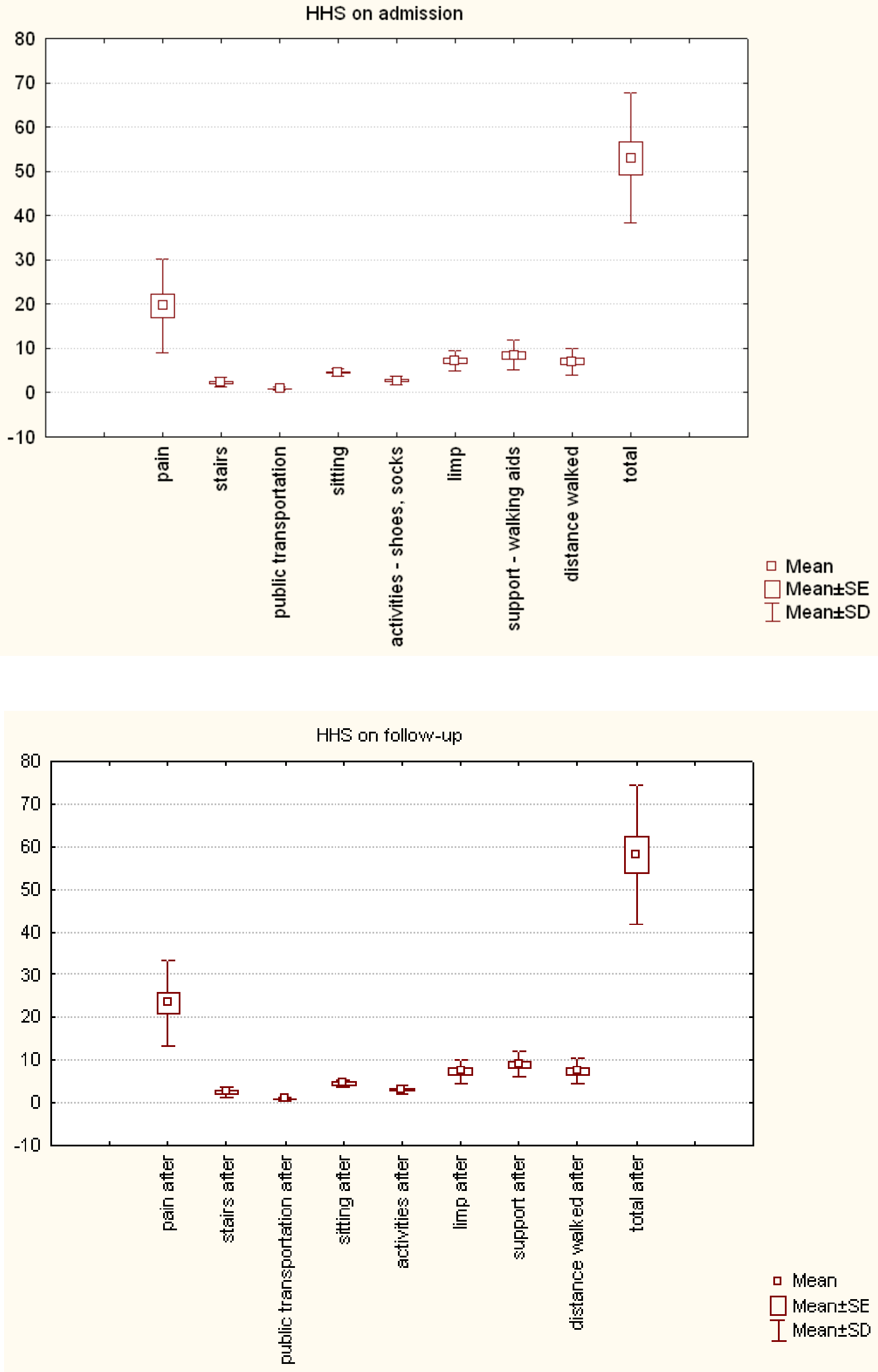